\title{
Heritage-language speakers: theoretical and empirical challenges on sociolinguistic attitudes and prestige
}

\author{
Jonathan R Kasstan
}

Department of Linguistics, Queen Mary University of London, UK

\author{
Anita Auer \\ Department of English, Université de Lausanne, $\mathrm{CH}$ \\ Joseph Salmons \\ Department of Linguistics, University of Wisconsin - Madison, USA
}

Migration brings people into situations where languages other than their native tongues are dominant. Their mother tongues often therewith become minority varieties, for young people and later generations what are now called 'heritage languages'. This particular kind of multilingual setting appears to correlate with consistent (but variable) processes of change. In the last few years, heritage-language research has been developing rapidly across subdisciplines as varied as heritage language education (Trifonas \& Aravossitas 2015; Kagan et al. 2017), language attrition (Köpke et al. 2007; Schmid 2011), and structural linguistics (see notably Benmamoun et al., 2010; 2013). While these research areas provide broadly detailed and comprehensive overviews on grammatical knowledge and grammatical change in the heritage-language context, less attention has to date been dedicated to sociolinguistic approaches and the role that specific external-linguistic factors play. In this special issue of the International Journal of Bilingualism, we foreground the role of external factors in heritage-language variation and change. More precisely, we are concerned with the questions of (a) what effect the prestige of related minority languages/language varieties has in the heritage-language context, and (b) how heritage-language speakers view and evaluate their own linguistic practices, notably also in relation to other languages/language varieties. Relatedly, the following considerations ${ }^{1}$ also frame the collection of articles presented herein:

- what were the reasons for leaving the hearth culture;

- in what environment and under what conditions do the heritage speakers find themselves in their new home;

- what motivations are there for language learning and/or language maintenance;

- what languages (or language varieties) are used in the family, in different social networks, communities of practice, and in the larger speech community;

- and what generation of heritage speaker characterises the object of study.

The fundamental factors above, language attitudes and prestige, are foregrounded here for they are both regularly and strongly implicated in processes of change relating to nonheritage contexts broadly, including in language maintenance and shift studies (see in

\footnotetext{
${ }^{1}$ These considerations reflect current debates in the field, see e.g. Polinsky \& Kagan (2007); Potowski (2013); Polinsky (forthcoming).
}

Corresponding author:

Jonathan R Kasstan, Department of Linguistics,

Queen Mary University of London,

Mile End Road, London, E14NS

Email: j.kasstan@qmul.ac.uk 
particular Trudgill, 1983, p. 129; Dorian, 1987, p. 63; Fishman, 1991, p. 174; Appel \& Muysken, 2006, pp. 32-45). However, in the broader research tradition of sociolinguistics and language change, both issues have long been treated with considerable nuance. Prestige, for instance, has already been discussed at length in Weinreich et al. (1968, pp. 123-124 and elsewhere) and serious challenges to the notion were later raised by Milroy (1989, 1992a, $1992 \mathrm{~b}$ ) who devotes significant attention to the fact that prestige as a notion is appealed to as an explanation for linguistic change in such a routine (and vague) way that it is often unclear what explanatory power it affords.

Similarly, appeals to language attitudes as an explanatory factor in change remain a rich area of inquiry in sociolinguistics, which has drawn heavily from social-psychological theories and frameworks in developing approaches to interpersonal communication and group boundaries. To take an example that bears directly on the present volume, models of (subjective) ethnolinguistic vitality are taken as a proxy for language attitudes in contact contexts. Under the framework proposed by Giles et al. (1977) and Giles (1979), members of groups who value their language may adopt strategies of psycholinguistic distinctiveness, such as accentuating ethnic speech markers and other salient linguistic features when communicating with out-group members. Conversely, where said value is lacking, strategies that attenuate to the dominant group may also be adopted (e.g. accommodation or assimilation). However, as has been pointed out by Liebkind (2010, pp. 23-24), low ethnolinguistic vitality does not necessarily entail such outcomes, as is often simplistically assumed in research that invokes social-psychological factors in explaining contact-induced change.

Recent studies addressing or invoking attitudes and prestige as they bear on maintenance and shift show that such factors continue to be taken as unproblematic predictors that can favour maintenance (an overview can be found in Lynch, 2014), but greater nuance is also emerging. In exploring motivations for maintaining a threatened variety in the United States, Haynes (2013) has identified that learners with positive attitudes towards heritage Indigenous languages did not tend to adopt the same perspective vis-à-vis other non-English varieties. She argues that the scarcity of available communal resources plays a role in her participants' attitudes, in that provisions for non-Native American varieties detract from the community's own goals of increased fluency in their own community's language (Haynes, 2013, p. 372). The factors at play, then, can be compartmentalised and can reflect particular complexities in multilingual communities. Language attitudes and prestige can also form an interface. Arnbjörnsdóttir (2015) identifies how attitudes pertaining to linguistic purism towards the Icelandic of Iceland have been transported along with the language to heritage Icelandic communities in North America. Therefore, the role of the standard language ideology (e.g. Lippi-Green, 2012; Milroy \& Milroy, 2013) needs to be considered as a potential factor in the maintenance of heritage languages, as does any potential bidirectionality in the pull from different sorts of language prestige in multilingual communities. This is because, in some cases, the heritage language can become a strong symbol of community cohesion in the host country. For instance, van den Berg (forthcoming, cited in Aalberse \& Muysken, 2013, p. 4) reports that Akan has become the community language of Ghanaian migrants in the Netherlands, even among those community members who would not normally speak Akan in Ghana. Such findings appear to contradict long-held assumptions about the nature of inter-ethnic communication and predicted patterns of language shift, as outlined in Giles (1979)'s classic model. That new arrivals to the community can come to speak a language connected with a superordinate ethnic group from the country of origin, which is not the language of the host country clearly has implications for broader questions on language variation and language change, and these contexts deserve 
greater attention (see Li \& Juffermans, 2016, on an analogous context concerning Cantonese speakers in the Netherlands).

Factor interaction between attitudes and prestige becomes even more nuanced when speaker agency is influenced by family language policy. As Polinsky and Kagan (2007, p. 377) point out, language attitudes harboured by heritage speakers' parents also have effects on heritage-language maintenance, where language policy in the home is often the deciding factor in the transmission of the minority variety (e.g. Spolsky, 2012). Any erosion of the home as an intact domain for the preservation of the minority variety is frequently argued to represent a terminal stage in language shift (e.g. Fishman, 1991; Romaine, 2000). It is reasonable to hypothesise, then, that positive attitudes held by parents towards the family heritage language will exert an influence on their children's rate of acquisition and maintenance (or decreased fluency and shift). In short, 'the more parents value and use the heritage language, the more their children tend to acquire and maintain it' (Gharibi \& Boers, 2017 b, p. 4), and this is supported by the available evidence to some extent. Luning \& Yamauchi (2010) for example identified that their community showed very disparate attitudes towards Kaiapuni immersion programmes in Hawaii, which emerged following a centurylong ban on the language in public schools. Years later, some parents of children enrolled on these programmes continue to be chastised by extended family members, who in their study, did not view such provisions favourably, as they had internalised longstanding negative attitudes towards the language (embodying what Wolfram, 1998 has termed the Linguistic Inferiority Principle). This is in spite of the fact that the programme described by Luning and Yamauchi emphasises traditional values and cultural pride (2010, p. 224).

In general, the wider literature does reveal a pattern of correlations between positive attitudes towards ethnic identity, and heritage-language maintenance (e.g. Extra \& Yagmur, 2010; Oh \& Fuligni, 2010; Prevoo et al., 2011). It therefore comes as no surprise that parental attitudes towards younger learners of heritage languages have been identified as a significant predictor of increased performance in structured-elicitation tasks too. For example, Au and Oh's (2005) study of Korean as a heritage language found that the language spoken by parents at home, as well as their attitudes towards home language and culture (measured by way of ethnic pride and discussions surrounding ethnic history and identity), correlated with the children's later abilities in the home language. However, recent studies that include more nuanced methodology have revealed more ambiguous observations on the impact of language attitudes held by parents. Most recently, Gharibi and Boers (2017a) investigated lexical fluency (using productive/receptive vocabulary tests) among 30 heritage Persian speakers (both simultaneous and sequential) living in New Zealand, comparing them with matched monolingual counterparts in Iran. The parents of each heritage participant in the study were interviewed about their language attitudes towards Persian. The results revealed that parental attitudes were found to be the strongest predictor of vocabulary knowledge, but only for simultaneous bilinguals. Conversely, for the sequential bilinguals, the analysis revealed that age of emigration was the deciding factor linked to vocabulary knowledge. In a follow-up study (Gharibi \& Boers, 2017b), the authors altered the methodology design by eliciting oral narratives over decontextualized elicitation tasks from the same sample of participants. The results from the revised methodology show that frequency of Persian use and parents' attitudes to heritage language maintenance 'did not appear to exert much of an influence on the heritage speakers' lexical richness' (p. 15).

While convincing evidence suggests that attitudes play a role in heritage-language proficiency, maintenance, and shift, we hasten to note that such factors may interact with (and may even be subordinate to) conditions of formal educational systems and broad community structures, as argued by Skutnabb-Kangas (2000) and cast in terms of 'verticalization' by Brown (forthcoming). The verticalization model connects language shift with a fundamental 
changes to community structure, where institutions and social groups are initially tightly intertwined and under local control, followed by a shift to extra-community control of key institutions, often including education, media and economic activity. Again, the sociolinguistic literature has already recognized the importance of such institutions in the propagation of traditional power structures, and, accordingly, the legitimation of language subordination (e.g. Lippi-Green, 1997), and future work in heritage-language linguistics will have to engage with these broader issues.

The above overview shows that heritage-language linguistics is rapidly developing a rich understanding of language structure on the one hand, but the roles of sociolinguistic factors such as language attitudes and ideologies are to date less developed in the heritagelanguage research culture. Far less work has so far attempted to bridge these two spheres, and this will be a central aim of the present issue. A fuller understanding of language change requires not only attention to both, but an integration of both into a coherent whole. In other areas of linguistics, most work has long since moved beyond what Dorian calls this kind of 'weakness of simplistic dichotomous thinking' (1993: 152).

A final consideration explored in this issue that has remained underexplored to date is a cross-linguistic dimension to - and thus a more systematic take on — research on attitude and prestige with regards to heritage languages. Much of the work in this area that does exist relates to independent language contexts with disparate methodology designs, and it is not clear what artefacts are cropping up in these varied datasets when examined as a whole. However, some comparative cross-linguistic work is beginning to emerge in heritagelanguage linguistics from the perspective of attitudes, with more consistent methodological protocols. Nagy (2015) adopts the comparative sociolinguistic framework (see Tagliamonte, 2013) in analysing production data among Toronto-based speakers of Heritage Cantonese, Italian and Russian. She reports that, cross-linguistically, no correlations emerged between the distribution of two sociolinguistic variables (null-subjects and voice-onset time) and language attitudes (measured through ethnic orientation) as an independent variable. In other words, language attitudes, be they positive or negative, showed only a weak effect on variation that patterned more like the dominant language, English, contra most individual cases reported elsewhere. Such findings highlight the importance of controlling for methodological protocols in cross-linguistic approaches to heritage-language variation and change. While the results are tantalising, important questions remain in terms of how language attitudes interact with other well-known macro- and micro-sociolinguistic variables. In spite of these novel efforts, then, it nonetheless remains the case that '[...] a major shortcoming of traditional work on heritage languages is that work on a given community has been done all too often in isolation from related work on other languages [...]' (Johannessen \& Salmons, 2015, p. 3).

With this état des lieux in mind, we wish to shed more light on the role(s) that attitudes and prestige play in the complex processes of heritage language maintenance, shift, variation, and change. Further, the volume adopts a cross-linguistic perspective, tying together strands of research that relate to attitudes and prestige, in typologically dissimilar language contexts. By adopting this approach, a further aim of the volume is to establish common crosslinguistic patterns that elucidate on our aforementioned objectives, and further refine methods for future research initiatives in heritage-language linguistics.

Having outlined the broad themes of this special issue, we turn now to more specific research avenues in which prestige and language attitudes can play very different roles:

- What is the nature of the relationships between language attitudes and prestige on the available language data? What, for instance, is the relationship between the homeland data and the heritage-language data: is one more 'standard' and, therefore, possibly perceived as more prestigious than the other; is there a relationship between the investigated heritage- 
language data and other related heritage-language varieties in the heritage communities; and what role does the host language play in relation to the heritage-language?

- Do issues of attitudes and prestige linked to different generations in the transmission and use of heritage languages differ, and if so, how do they differ?

- How are the notions of 'prestige' and 'attitude' perceived and discussed in heritage-language studies? These notions have been challenged or problematized in sociolinguistics and the study of language change. For heritage-language linguistics, can clear trends be determined that allow us to think about these notions in a rigorous, careful and more uniform way? For instance, in statistical modelling within and across languages, what correlations emerge between dependent variables (linguistic features) and attitudes/language prestige as independent variables?

Addressing the above questions produced contributions from a range of (socio)linguistic fields of inquiry with very different but complimentary analytical lenses and theoretical frameworks. Our first contribution comes from Moro, who considers the effect of socialpsychological factors (including language attitudes and social-network structure) on increased use of Dutch-like features in heritage Ambon Malay among speakers in the Netherlands. She reports that positive attitudes towards Ambon Malay in her sample promote more frequent use of the language (and thus greater rates of maintenance), but these attitudes are also correlated with the introduction of greater rates of contact-induced Dutch innovations into the heritage language. Moro considers the effects of this compromise on heritage-language speakers.

Karatsareas then explores whether or not language attitudes vis-à-vis both Standard Modern Greek and Cypriot Greek in Cyprus have been transported to London's Greek Cypriot community. Drawing on qualitative data taken from semi-structured sociolinguistic interviews among 28 heritage speakers, he finds that Cypriot Greek is denigrated among its users in London by comparison with Standard Modern Greek, and Greek complementary schools are found to play a key role in engendering these attitudes. Increasingly, he finds that Cypriot Greek is discouraged in the most intimate domains of usage. To a certain extent, these observations on the portability of purist attitudes towards the heritage language complement findings described above in Arnbjörnsdóttir (2015).

Nagy considers how best to operationalize notions of 'prestige' and 'attitude' in the context of a large-scale heritage-language variation and change project in Toronto (Canada). She takes speech samples from heritage languages with very different types of status in both the homeland and heritage context (Francoprovençal, Italian, Korean, Polish, Russian and Ukrainian), and compares them with their homeland counterparts. Nagy uses multivariate analysis in order to determine which predictors best account for the selection of competing linguistic variants of a series of linguistic variables in spontaneous speech. The attitudinal and prestige aspects are explored in several ways: including a comparison of ethnolinguistic vitality, language status (in popular and academic media), and ethnic orientation. Overall, she finds these factors to have little impact on the variability in her datasets overall (cf. Nagy, 2015).

Johannessen then assess which factors are most often found to influence variation and change specifically in 'Heritage Scandinavian' in North America. In adopting a critical comparative approach, she produces fresh insights concerning both internal- and externalfactor interaction in language contact. The role of attitudes operating on language maintenance and competency is found to be much more graded than most analyses suggest. In general, while speakers maintain strong positive attitudes towards their heritage varieties, Johannessen reveals very little effect played by attitudes at the individual level. At the community level, she reinforces an emergent view that vertical ties (see above) may play a more prominent role in the maintenance process than horizontal ties, which would better 
explain the marked decline in e.g. Heritage Norwegian since the 1970s than speaker attitudes alone.

Lastly, Sánchez, Mayer, Camacho and Rodriguez Alzza consider language attitudes among speakers of Shipibo (Panoan) spoken in Spanish-dominant Lima (South America). Their sample of speakers, who come from a community in Cantagallo, were interviewed on two occasions: first during early settlement in 2002, and again in 2017 following resettlement. Using sociolinguistic questionnaire data, they report that language shift can be traced in realtime (particularly in the youngest generation), despite very strong positive attitudes towards the heritage variety. Their contribution foregrounds the flaws in a simple dichotomous model that seeks to draw relationships between language attitudes (negative/positive) and language change. Instead, the authors highlight the importance of considering language attitudes as dynamic, with a capacity to both shape the sociolinguistic field, and be shaped by them.

In sum, it is clear from this overview that our broad understanding of complex and diverse heritage-language settings is now progressing rapidly. However, gaps in our knowledge remain, and this issue assembles the pieces of more local understanding into a more coherent whole, with balance between the internal and external - and some first stirrings of integration of the two - in order to offer some new comparative perspectives.

\section{Acknowledgements}

We thank the contributing authors for their creative and careful work. We also thank the anonymous reviewers for their diligent efforts and IJB for their editorial support.

\section{References}

Aalberse, S. \& Muysken, P. (2013). Perspectives on heritage languages. Position paper for the workshop Structural Changes in Heritage Languages, $23^{\text {rd }}-25^{\text {th }}$ January, Radbound University.

Appel, R. \& Muysken, P. (2016). Language Contact and Bilingualism. Amsterdam: Amsterdam University Press.

Arnbjörnsdóttir, Birna. (2015). Re-examining Icelandic as a heritage language in North America. In J. B. Johannessen \& J. Salmons (Eds.), Germanic Heritage Languages in North America: Acquisition, Attrition and Change (pp. 72-97). Amsterdam, NL: John Benjamins.

Au, T. \& Oh, J. (2005). Korean as a heritage language. In L. Ping (Ed.), Handbook of East Asian Psychology (pp. 268-275). Cambridge, UK: Cambridge University Press.

Benmamoun, E., Montrul, S. \& Polinsky, M. (2010). White Paper: Prolegomena to Heritage Linguistics. Boston, US: Harvard University Press.

Benmamoun, E., Montrul, S. \& Polinsky, M. (2013). Heritage languages and their speakers: Opportunities and challenges for linguistics. Theoretical Linguistics, 39(3-4), 129-181.

van den Berg, M. (Forthcoming). Akan/Twi and Ewe: Levelling and multiple lingua francas. In S. Aalberse \& P. Muysken (Eds.), Heritage Languages in the Netherlands: Patterns of Variation and Adoption.

Brown, J. (Forthcoming). Verticalization: A model for language shift.

Dorian, N. C. (1987). The value of language-maintenance efforts which are unlikely to succeed. International Journal of the Sociology of Language, 68, 57-67.

Dorian, N. C. (1993). Internally and externally motivated change in language contact settings: Doubts about the dichotomy. In C. Jones (Ed.), Historical Linguistics: Problems and Perspectives (pp. 131-155). London, UK: Longman.

Fishman, J. A. (1991). Reversing Language Shift: Theoretical and Empirical Foundations of Assistance to Threatened Languages. Clevedon: Multilingual Matters. 
Gharibi, K. \& Boers, F. (2017a). Influential factors in incomplete acquisition and attrition of young heritage speakers' vocabulary knowledge. Language Acquisition, 24(1), 52-69.

Gharibi, K. \& Boers, F. (2017b). Influential factors in lexical richness of young heritage speakers' family language: Iranians in New Zealand. International Journal of Bilingualism, OnlineFirst, 1-19.

Giles, H. Bourhis, R. Y. \& Taylor, D. M. (1977). Towards a theory of language in ethnic group relations. In H. Giles (Ed.), Language, Ethnicity and Intergroup Relations (pp. 307-348). London, UK: Academic Press.

Giles, H. (1979). Ethnicity markers in speech. In K. R. Scherer \& H. Giles (Eds.), Social Markers in Speech (pp. 291-342). Cambridge, UK: Cambridge University Press.

Haynes, E. F. (2013). The role of desire, opportunity, and capacity in the revitalization of Native American languages. Heritage Language Journal, 10(3), 367-381.

Johannessen, J. B. \& Salmons, J. C. (2015). The study of Germanic heritage languages in the Americas. In J. B. Johannessen \& J. C. Salmons (Eds.), Germanic Heritage Languages in North America: Acquisition, attrition and change (pp. 200-322). Amsterdam, NL: John Benjamins.

Kagan, O., Carreira, M. M. \& Hitchens C. C. (Eds.) (2017). The Routledge Handbook of Heritage Language Education: From Innovation to Programme Building. Abingdon, UK: Routledge.

Köpke, B., Schmid, M. S., Kejzer, M. \& Dostert, S. (Eds.) (2007). Language Attrition: Theoretical Perspectives. Amsterdam, NL: John Benjamins.

Li, J. \& Juffermans, K. (2016). Constructing Dutch-Chinese youth identities in the classroom and online. In: W. Li (ed.), Multilingualism in the Chinese Diaspora Worldwide: Transnational Connections and Local Social Realities (pp. 32-46). Abingdon: Routledge.

Liebkind, K. (2010). Social Psychology. In J. A. Fishman \& O. García (Eds.), Handbook of Language and Ethnic Identity (pp. 18-31). Oxford, UK: Oxford University Press.

Lippi-Green, R. L. (1997). English with an Accent: Language, Ideology, and Discrimination in the United States. London, UK: Routledge.

Lippi-Green, R. L. (2012). English with an Accent: Language, Ideology and Discrimination in the United States. 2nd edn. London, UK: Routledge.

Luning, R. J. I. \& Yamauchi, L. A. (2010). The influences of indigenous heritage language education on students and families in a Hawaiian language immersion programme. Heritage Language Journal, 7(2), 207-236.

Lynch, A. (2014). The first decade of the Heritage Language Journal: A retrospective view of research on heritage languages. Heritage Language Journal, 11(3), 224-242.

Milroy, J. (1989). The concept of prestige in sociolinguistic argumentation. York Papers in Linguistics, 13, 215-226.

Milroy, J. (1992a). Linguistic Variation \& Change: On the Historical Sociolinguistics of English. Oxford, UK: Oxford University Press.

Milroy, J. (1992b). Social network and prestige arguments in sociolinguistics. In K. Bolton and H. Kwok (Eds.), Sociolinguistics Today: International Perspectives (pp. 146-162). London, UK: Kingsley Bolton.

Milroy, J. \& Milroy, L. (2013). Authority in Language: Investigating Standard English. 4th ed. London, UK: Routledge.

Nagy, N. (2015). A sociolinguistic view of null subjects and VOT in Toronto heritage languages. Lingua, 164, 309-327.

Prevoo, M. J. L., Mesman, J., Van Ijzendoorn, M. H. \& Pieper, S. (2011). Bilingual toddlers reap the language they sow: ethnic minority toddlers' childcare attendance increases 
maternal host language use. Journal of Multilingual and Multicultural Development, 32(6), 561-576.

Polinsky, M. (Forthcoming). Heritage languages and their speakers. Cambridge, UK: Cambridge University Press.

Polinsky, M. \& Kagan, O. (2007). Heritage languages: in the 'wild' and in the classroom. Language \& Linguistic Compass, 1(5), 368-395.

Potowski, K. (2013). Language maintenance and shift. In R. Bailey, R. Cameron \& C. Lucas (Eds.), The Oxford Handbook of Sociolinguistics (pp. 321-339). Oxford, UK: Oxford University Press.

Romaine, S. (2000). Language in Society: An Introduction to Sociolinguistics (2 ${ }^{\text {nd }}$ Ed.). Oxford, UK: Oxford University Press.

Schmid, M. S. (2011). Language Attrition. Cambridge, UK: Cambridge University Press.

Skutnabb-Kangas, T. (2000). Linguistic Genocide in Education - or Worldwide Diversity and Human Rights? Mahwah, US: Erlbaum.

Tagliamonte, S. (2013). Comparative Sociolinguistics. In J. K. Chambers \& N. Schilling (eds.), The Handbook of Language Variation and Change (pp. 128-156). Oxford, UK: Wiley-Blackwell.

Trifonas, P. P. \& Aravossitas, T. (Eds.) (2014). Rethinking Heritage Language Education. Cambridge, UK: Cambridge University Press.

Trudgill, P. (1983). Language contact, language shift and identity: Why Arvanites are not Albanians. In P. Trudgill (Ed.), On Dialect: Social and Geographical Perspectives (pp. 127-140). Oxford, UK: Blackwell.

Weinreich, U., Labov, W. \& Herzog, M. I. (1968). Empirical foundations for a theory of language change. In W. P. Lehmann \& Y. Malkiel (Eds.), Directions for Historical Linguistics: A Symposium (pp. 97-195). Austin, US: University of Texas Press.

Wolfram, W. (1998). Black children are verbally deprived. In L. Bauer \& P. Trudgill (Eds.), Language Myths (pp. 142-152). London, UK: Penguin. 